\title{
Virulence stability in Flavobacterium psychrophilum after storage and preservation according to different procedures
}

\author{
Christian MichEL ${ }^{\mathrm{a} *}$, Céline GARCIA ${ }^{\mathrm{b}}$ \\ a Institut National de Recherche Agronomique, Unité de Virologie et d'Immunologie Moléculaires, \\ Centre de Recherches de Jouy-en-Josas, 78352 Jouy-en-Josas Cedex, France \\ ${ }^{\mathrm{b}}$ Institut Français de Recherche pour l'Exploitation de la Mer, Station de la Trinité, \\ 12 rue des Résistants, BP 80, 56470 La Trinité-sur-Mer, France
}

(Received 16 May 2002; accepted 16 August 2002)

\begin{abstract}
Experimental infections and lethal dose 50\% $\left(\mathrm{LD}_{50}\right)$ evaluation were conducted in rainbow trout fingerlings, using a virulent strain of Flavobacterium psychrophilum processed and stored or maintained in different ways; lyophilisation, freezing at $-80^{\circ} \mathrm{C}$, maintenance in enriched Anacker and Ordal (EAO) medium at $4{ }^{\circ} \mathrm{C}$, revival and subsequent in vivo passages in fish. Experiments were performed 1, 8 and 23 months after storing the bacteria. Out of a total of 12 cultures revived for experimentation, one failed to grow and another was found to express modified properties including decreased virulence in spite of in vivo passages. In all other cases, whatever the conditions of preservation, virulence was fairly well maintained after 1 and 8 months of storage. In the last test, after 23 months, the bacteria maintained in the EAO medium at $4{ }^{\circ} \mathrm{C}$ were found significantly attenuated. Conversely, lyophilised and frozen bacteria only expressed a slight increase in $\mathrm{LD}_{50}$. It was concluded that virulent strains of $F$. psychrophilum were likely to retain their properties without special provisions within limited periods of time, and that both lyophilisation and freezing at $-80^{\circ} \mathrm{C}$ were reliable methods for long-term preservation of virulence.
\end{abstract}

fish disease / bacteria / Flavobacterium psychrophilum / virulence / preservation

\section{INTRODUCTION}

Stability of virulent properties is a difficult problem for microbiologists working with pathogenic bacteria. Since the very first observation that partial or complete loss of virulence could result from aged bacterial cultures grown in artificial media, which helped in the development of the first vaccination concepts by Pasteur, the influence of in vitro culture conditions favouring the occurrence of avirulent mutants has been confirmed in many species [14]. The same is true with fish pathogens. A demonstrative example is the early work with Aeromonas salmonicida which formed "rough" colonies and, for a while, was thought to possess properties similar to those of Salmonellae. This was invalidated when Udey and Fryer [16] described

\footnotetext{
* Correspondence and reprints

Tel.: (33) 1346525 86; fax: (33) 1346525 91; e-mail: michel@jouy.inra.fr
} 
the superficial A-layer of the bacterium. Subsequently, all the authors who handled this pathogen noticed the high frequency of the A-layer negative and avirulent forms development during subculture $[2,5,6]$, and in depth investigations into the structural, biochemical and genetic properties of the A-layer were made easier by the availability of defective mutants [7].

For these reasons, maintenance of virulent strains is a prerequisite when relying on experimental infection as a research or routine tool. The most common approach consists of serial in vivo passages through susceptible animals, so offering the closest imitation of natural infection. This was done with success by McCarthy [11], working at improving experimental infections with the furunculosis agent Aeromonas salmonicida. In the case of Flavobacterium psychrophilum, a gliding bacterium responsible for serious infections including septicaemia observed mainly in rainbow trout (Oncorhynchus kisutch) fry in Europe, and called rainbow trout fry syndrome (RTSF) [8, 9], difficulties clearly linked to physiological requirements of the bacterium were long encountered. Thus, the control of strictly conducted experimental infections has been achieved only recently $[4,10]$. Since standardised and reliable models have become available, relatively few studies have examined the discrimination between virulent and avirulent forms. Even when such form distinctions are made, they are generally not based on objective criteria.

Standardised procedures for experimental disease were used to show whether the virulence of the bacteria changed with storage time and conservation methods.

\section{MATERIALS AND METHODS}

\subsection{Fish}

Rainbow trout eggs, purchased from a fish farm in the Jura with no history of
RTFS [4] were disinfected with iodine on arrival and hatched in the INRA experimental facilities of Jouy-en-Josas, France. Fish were reared in $16 \mathrm{~L}$ aquaria arranged in a recirculating unit, supplied with dechlorinated, UV-sterilised and aerated tap water regulated at $10^{\circ} \mathrm{C}$. They were fed a commercial dried pellet $1 \%(\mathrm{~W} / \mathrm{W})$ and sorted at regular intervals to avoid excessive size heterogeneity. Two experiments were conducted on trout from a same cohort, respectively in 1999 (mean weight $5.1 \mathrm{~g}$ ) and 2000 (mean weight $11 \mathrm{~g}$ ). Another cohort of trout from the same broodstock (mean weight $5.9 \mathrm{~g}$ ) was used in 2001. One week before experimental infection, the fish were arranged in groups of 10 and transferred to similar aquaria supplied with flow-through water at $10^{\circ} \mathrm{C}$. Outlet water was treated with chlorine before being drained towards an epuration plant.

\subsection{Bacterial strain and preservation procedures}

Fresh cultures of the virulent Flavobacterium psychrophilum strain JIP P29-98, already used in previous experiments [4], had been processed according to different methods immediately after isolation from experimentally infected fish. Samples were frozen dried after suspension in Brucella broth (Difco) enriched with 33\% horse serum [3], and stored at $4{ }^{\circ} \mathrm{C}$ until use. Other cultures were suspended in casitone liquid medium [15] supplemented with $10 \%$ glycerol as a preservation agent, and frozen at $-80^{\circ} \mathrm{C}$. For comparison purposes, bacteria stored at $4{ }^{\circ} \mathrm{C}$ in enriched Anacker and Ordal (EAO) medium [1] containing $0.4 \%$ agar were used in every experiment, directly or after 3 to 4 serial in vivo passages. In this last case, $48 \mathrm{~h}$ broth cultures produced at $18{ }^{\circ} \mathrm{C}$ immediately after reviving or reisolating the bacteria were diluted to $10^{-1}$ and injected into rainbow trout via the intra-muscular (IM) route. 
Table I. Stability of the virulence of the F. psychrophilum strain JIP P29-98 in rainbow trout: protocols and results of the infection trials establishing the $\mathrm{LD}_{50}$ of the bacterium held under several conditions and delivered to fish by intramuscular injections.

\begin{tabular}{|c|c|c|c|}
\hline $\begin{array}{l}\text { Experimental series } \\
\text { and conservation method } \\
\text { of the bacterium }\end{array}$ & $\begin{array}{l}\text { Theoretical doses }{ }^{\mathrm{a}} \\
\text { (cfu per fish) }^{\mathrm{c}}\end{array}$ & $\begin{array}{l}\text { Real doses }{ }^{b} \\
\text { (cfu per fish) }^{c}\end{array}$ & $\begin{array}{l}\mathrm{LD}_{50}{ }^{\mathrm{d}} \\
(\mathrm{cfu})^{\mathrm{c}}\end{array}$ \\
\hline \multicolumn{4}{|c|}{ 1st experiment (1 month, fish $5.1 \mathrm{~g}$ ) } \\
\hline Lyophilisation & $10-10^{6}$ & $20-1.9810^{6}$ & 33 \\
\hline Freezing $-80^{\circ} \mathrm{C}$ & $10-10^{6}$ & $16-1.6210^{6}$ & 65 \\
\hline Culture medium $4{ }^{\circ} \mathrm{C}$ & $10-10^{6}$ & $16-1.6110^{6}$ & 268 \\
\hline In vivo passages & $10-10^{6}$ & $18-1.8310^{6}$ & 137 \\
\hline \multicolumn{4}{|c|}{ 2nd experiment ( 8 months, fish $11 \mathrm{~g}$ ) } \\
\hline Lyophilisation & $11-1.0610^{6}$ & $1-1.4210^{5}$ & $95(30)$ \\
\hline Freezing $-80^{\circ} \mathrm{C}$ & $13-1.2810^{6}$ & $2-2.3910^{5}$ & $240(13)$ \\
\hline Culture medium $4{ }^{\circ} \mathrm{C}$ & failure in revival & & \\
\hline In vivo passages & $12-1.1710^{6}$ & $1-1.2210^{5}$ & $67(38)$ \\
\hline \multicolumn{4}{|c|}{ 3rd experiment (23 months, fish $5.9 \mathrm{~g}$ ) } \\
\hline Lyophilisation & $50-510^{5}$ & $39-3.9110^{5}$ & 7801 \\
\hline Freezing $-80{ }^{\circ} \mathrm{C}$ & $50-510^{5}$ & $22-2.1610^{5}$ & 1237 \\
\hline Culture medium $4{ }^{\circ} \mathrm{C}$ & $50-510^{5}$ & $27-2.6810^{5}$ & $1.6910^{5}$ \\
\hline In vivo passages & $50-510^{5}$ & $?$ (failure) & $3.610^{4} ?^{\mathrm{a}}$ \\
\hline
\end{tabular}

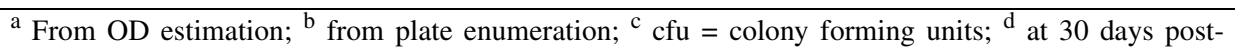
infection, except another assessment at 40 days (brackets) in the 2 nd experiment.

\subsection{Infection procedures}

Three series of trials were conducted after 1,8 and 23 months of conservation respectively. In each series, bacteria processed or maintained in different ways were grown in $250 \mathrm{~mL}$ Erlenmeyer flasks containing $100 \mathrm{~mL}$ of EAO broth supplemented with $5 \%$ horse serum and $0.02 \%$ trace element solution [12]. According to previously described procedures [4], the cultures were incubated for $48 \mathrm{~h}$ at $18{ }^{\circ} \mathrm{C}$ in an orbital shaker $(80 \mathrm{rpm})$. After measuring the absorption of the cultures at $525 \mathrm{~nm}$ in a Camspec M 330 spectrophotometer (Kontron, France), serial tenfold step dilutions were performed in saline $0.9 \%$, and control enumeration was performed on EAO solid medium supplemented with horse serum 5\%, using the droplet technique of Miles and Misra [13].

For the assessment of the lethal dose $50 \%\left(\mathrm{LD}_{50}\right)$, fish were not fed for $24 \mathrm{~h}$ and were anaesthetised in $0.3 \mathrm{~mL} \cdot \mathrm{L}^{-1} 2$-phenoxyethanol, then 0.05 or $0.1 \mathrm{~mL}$ (according to fish size) of tenfold dilutions of the different bacterial suspensions were injected IM in order to provide increasing doses to the different groups. To comply with the experimental constraints, 5 groups per series instead of 6 were used in experiment 3 , and the dose adjustment had to be adapted (see Tab. I). The attribution 
Table II. Values and limits of confidence (brackets) of the $\mathrm{LD}_{50}$ of differently maintained F. psychrophilum cultures. Assuming the underestimation of the infective doses injected in the 2 nd experiment, values and result comparisons were computed from both plate enumeration (PE) results and optical density (OD) adjustment values.

\begin{tabular}{lcccc}
\hline Experiment & Lyophilisation & Freezing $-80^{\circ} \mathrm{C}$ & Culture medium & In vivo passages \\
\hline $\begin{array}{l}\mathbf{1}(1 \text { month }) \\
\mathbf{2}(8 \text { months) } \\
\text { from PE }\end{array}$ & $33(11-97)$ & $65(26-161)$ & $268(87-829)$ & $137(40-466)$ \\
$\quad$ day 30 & $95(42-218)$ & $240(46-1264)$ & ND & $67(17-330)$ \\
$\quad$ day 40 & $30(13-70)$ & $13(8-23)$ & - & $38(9-166)$ \\
$\quad$ from OD & & & - & $658\left(27-15.810^{3}\right)$ \\
day 30 & $722(139-3757)$ & $1280\left(46-35.510^{3}\right)$ & - & $370(19-7053)$ \\
$\quad$ day 40 & $228(42-1230)$ & $72(24-220)$ & - & $3610^{3}$ \\
$\mathbf{3}(23$ months $)$ & 7801 & 1237 & $16910^{3}$ & \\
& (ND) & $(413-3703)$ & $\left(64.510^{3}-44310^{3}\right)$ & $\left(11.610^{3}-11210^{3}\right)^{a}$ \\
\hline
\end{tabular}

${ }^{\mathrm{a}}$ From OD estimation.

of a particular bacterial suspension and dose to each group of 10 fish was decided on a random basis in order to prevent aquaria-linked bias. Injections of saline were performed similarly in 2 groups of control fish. Mortality was recorded for 30 days (40 days in the 2 nd experiment), and the dead fish were subjected to bacteriological screening.

\section{RESULTS}

Mortality occurred in all the infected groups of fish, except in controls injected with saline. Times to death varied according to the doses. At the 3 highest doses, it ranged from 6 to 13 days in the first experiment, from 12 to 17 days in the second experiment, from 9 to 24 days in the last experiment. In all cases the cumulative mortality curve was sigmoid, and a dose effect was generally reflected both in the incubation time and in the maximum level of mortality.

Tables I and II feature the conditions under which the different control tests were performed and the different results obtained after calculation of the $\mathrm{LD}_{50}$. It may be noticed that, although the standardised infection procedure generally produced the expected effect, exceptions occurred. Out of a total of 12 revived cultures, one failed to grow (experiment 2) and another was found to express modified properties including decreased virulence in spite of the in vivo passages (experiment 3). Whatever the conditions of preservation, however, virulence was maintained after 1 and 8 months of storage. In the last experiment only, after 23 months, the bacteria maintained in the EAO medium at $4{ }^{\circ} \mathrm{C}$ were found attenuated while lyophilised and frozen bacteria only expressed a slight increase in $\mathrm{LD}_{50}$.

Table II displays the same results with the limits of confidence for each calculation. Since the mortality in experiment 2 appeared lower than expected, $\mathrm{LD}_{50}$ based on the doses computed from optical density were also introduced for comparison. It may be seen that in most cases fish mortality was high, and that the virulence of the strain was maintained high enough to allow reliable use in experimental challenges. 


\section{DISCUSSION}

It must be noted that experiments 1 and 2 were performed in fish from the same cohort, so that the only factor of variation should theoretically have resulted from a difference in their size and weight. In fact, an experimental modification was inadvertently introduced in experiment 2 , so that the computations performed after the enumeration of the controls in this experiment are likely to have been underestimated. The wrong step was the introduction of mineral trace solution in the dishes on which control enumerations were performed. We had previously observed [12] that enrichment with mineral traces, although useful for ensuring better viability of $F$. psychrophilum, was not to be repeated in every subculture, for fear of introducing an inhibitory effect. The present results seem to confirm this phenomenon. Culturable colony counting provided unusual low values, and it was assumed that the real colony forming unit concentrations in the infectious suspensions injected to fish were rather in accordance with the OD predictions. If so, the corrections tentatively displayed in Table II restore more logical figures in comparison to the values assessed in the first series of tests. Apart from these considerations, and setting aside the case of the EAO-conserved bacteria, which failed to be revived and thus were not tested, it appears that the virulence of strain P29-98 had not greatly changed after 8 months of conservation.

Another important remark to mitigate the interpretative value of quantitative approaches in such experiments stems from the comparison of the $\mathrm{LD}_{50}$ respectively computed at days 30 and 40 in the second assay. Consistent differences appeared in the $\mathrm{LD}_{50}$, although few fish died between days 30 and 40. For instance, in the group injected with the in vivo maintained strain, a single fish died in the group having received $1.1710^{4}$ bacteria, resulting in a decrease of about $40 \%$ in the $\mathrm{LD}_{50}$.
The difference in the group injected with frozen bacteria was more representative of the mortality evolution. It is clear, however, that tiny experimental variations may affect the figures and that such results should be interpreted as orders of magnitude rather than absolute values.

The third experiment led to higher $\mathrm{LD}_{50}$ values in all groups of fish. Some difficulties were experienced with the strain subjected to in vivo passages. In this last case, the bacterial growth kinetics was unusually delayed, and the enumeration failed to produce detectable colonies. The protocol was repeated with the same results. We concluded that the problem probably stemmed from the properties of the strain itself and that some physiological modification or mutation could have occurred. This possibility is supported by the decrease in virulence deduced from the theoretical injected doses, although the in vivo passages are normally considered one of the best ways to preserve pathogenicity. The relatively high $\mathrm{LD}_{50}$ observed with the bacteria merely maintained on culture media may also indicate a loss of virulence, which became effective after 23 months of conservation. With lyophilised and frozen bacteria, the decrease in virulence remained limited. This was more difficult to interpret because the trout, although originating from the same fish farm broodstock as the formerly used ones, were probably from different breeders. Even though a slight impairment of bacterial properties through the time of storage cannot be ruled out, within population variability in the susceptibility of trout may also be considered.

On the whole, two conclusions of practical value may be drawn from this work. The classical conservation methods, freezing and lyophilisation, proved to be effective when applied to $F$. psychrophilum virulent cultures, and in so doing, the pathogenicity could be preserved for about 2 years without a significant loss of intensity. It is noteworthy that this bacterium 
may remain virulent long enough, even when merely stored at $4{ }^{\circ} \mathrm{C}$ on an EAO medium, as illustrated in the second experiment. The next point also results from the observations made in this experiment. This was the first time that relatively large fish $(11 \mathrm{~g})$ were used to attempt to reproduce the septicaemic form of cold water disease. In natural conditions this form of the disease is observed in very young animals, hence the name of RTSF, older animals being rather proned to exhibit skin and muscle infection. From our results, however, it does not seem that size and age are of critical importance for experimental susceptibility as long as the fish are naive and have not experienced former contact with the bacterium. All these characteristics confer a certain degree of versatility in the use of the experimental model of infection previously proposed. We are inclined to conclude that the reliability of our model is only limited by accidental culture events linked to intrinsic bacterial properties.

\section{ACKNOWLEDGEMENTS}

The authors specially appreciated the technical help provided by E. Letellier and F. Tiquet during the experimental work that was conducted in the INRA experimental facilities of Jouy-en-Josas.

\section{REFERENCES}

[1] Bernardet J.-F., Kerouault B., Phenotypic and genomic studies of "Cytophaga psychrophila" isolated from diseased rainbow trout (Oncorhynchus mykiss) in France, Appl. Environ. Microbiol. 55 (1989) 1796-1800.

[2] Cipriano R.C., Bertolini J., Selection for virulence in the fish pathogen Aeromonas salmonicida, using Coomassie brilliant blue agar, J. Wildl. Dis. 24 (1988) 672-678.

[3] Desolme B., Bernardet J.-F., Freeze-drying of Flavobacterium columnare, Flavobacterium psychrophilum, and Flexibacter maritimus, Dis. Aquat. Org. 27 (1996) 77-80.

[4] Garcia C., Pozet F., Michel C., Standardization of experimental infection with Flavobacterium psychrophilum, the agent of rainbow trout Oncorhynchus mykiss fry syndrome, Dis Aquat. Org. 42 (2000) 191-197.
[5] Ishiguro E.E., Kay W.W., Ainsworth T., Chamberlain J.B., Austen R.A., Buckley J.T., Trust T.J., Loss of virulence during culture of Aeromonas salmonicida at high temperature, J. Bacteriol. 148 (1981) 333-340.

[6] Kay W.W., Buckley J.T., Ishiguro E.E., Phipps B.M., Monette J.P.L., Trust T.J., Purification and disposition of a surface protein associated with virulence of Aeromonas salmonicida, J. Bacteriol. 147 (1981) 10771084.

[7] Kay W.W., Trust T.J., The surface of Aeromonas salmonicida: what doe it look like and what does it do?, in: Bernoth E.-M., Ellis A.E., Midtlyng P.J., Olivier G., Smith P. (Eds.), Furunculosis. Multidisciplinary fish disease research, Academic Press, San Diego, CA, London, UK, 1997, pp. 235-247.

[8] Lorenzen E., Dalsgaard I., From J., Hansen E.M., Hørlyck, V., Korsholm H., Mellergaard S., Olesen N.J., Preliminary investigations of fry mortality syndrome in rainbow trout, Bull. Eur. Ass. Fish. Pathol. 11 (1991) 77-79.

[9] Lorenzen E., Olsen N.J., Characterization of isolates of Flavobacterium psychrophilum associated with coldwater disease or rainbow trout fry syndrome II: serological studies, Dis. Aquat. Org. 31 (1997) 209-220.

[10] Madsen L., Dalsgaard I., Reproducible methods for experimental infection with Flavobacterium psychrophilum in rainbow trout Oncorhynchus mykiss, Dis. Aquat. Org. 36 (1999) 169-176.

[11] McCarthy D.H., Some aspects of the virulence of Aeromonas salmonicida, causative agent of furunculosis, Can. Fed. Biol. Soc. 19 (1976) 158.

[12] Michel C., Antonio D., Hedrick R.P., Production of viable cultures of Flavobacterium psychrophilum: approach and control, Res. Microbiol. 150 (1999) 351-358.

[13] Miles A.A., Misra S.S., The estimation of the bacteriocidal power of the blood, J. Hyg. 38 (1938) 732-749.

[14] Mims C.A., The pathogenesis of infectious diseases, Academic Press, London, New York, San Francisco, 1976, 246 p.

[15] Reichenbach H., The order Cytophagales, in: Balows A., Trüper H.G., Dworkin M., Harder W., Schleifer K.-H. (Eds.), The Procaryotes, Springer-Verlag, New York, Berlin, Heidelberg, 1992, pp. 3631-3675.

[16] Udey L.R., Fryer J.R., Immunization of fish with bacterins of Aeromonas salmonicida, Mar. Fish. Rev. 40 (1978) 12-17. 